Portland State University

PDXScholar

5-13-1996

\title{
Children with Early Language Delay: A Group Case Study of Outcomes in Intermediate Grades
}

Tracey Abild-Lane

Portland State University

Follow this and additional works at: https://pdxscholar.library.pdx.edu/open_access_etds

Part of the Speech and Rhetorical Studies Commons

Let us know how access to this document benefits you.

\section{Recommended Citation}

Abild-Lane, Tracey, "Children with Early Language Delay: A Group Case Study of Outcomes in Intermediate Grades" (1996). Dissertations and Theses. Paper 4953.

https://doi.org/10.15760/etd.6829

This Thesis is brought to you for free and open access. It has been accepted for inclusion in Dissertations and Theses by an authorized administrator of PDXScholar. Please contact us if we can make this document more accessible: pdxscholar@pdx.edu. 
THESIS APPROVAL

The abstract and thesis of Tracey Abild-Lane for the Master of Science in Speech Communication: Speech and Hearing Science were presented May 13,1996 , and accepted by the thesis committee and the department.

COMMITTEE APPROVALS

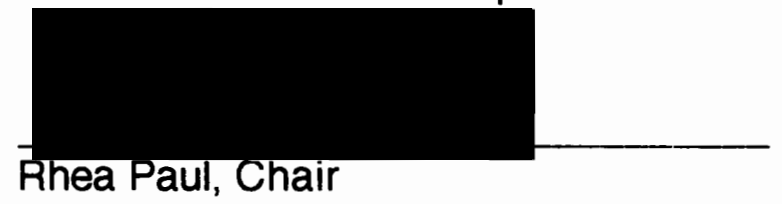

Ellen Reuler

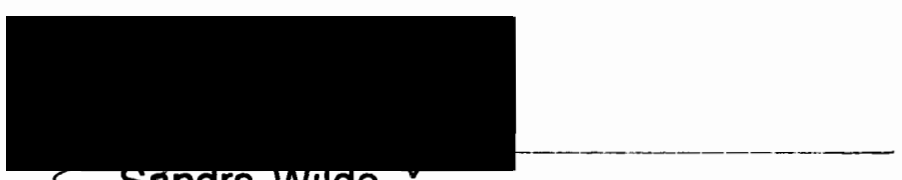

Senara wiloe

Representative of the Office of Graduate Studies

DEPARTMENT APPROVAL:

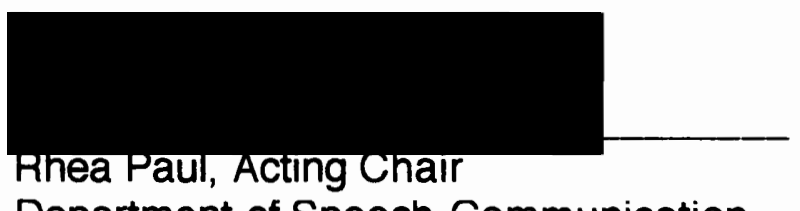

Department of Speech Communication

ACCEPTED FOR PORTLAND STATE UNIVERSITY BY THE LIBRARY by on

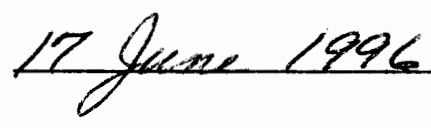




\section{ABSTRACT}

An abstract of the thesis of Tracey Abild-Lane for the Master of Science in Speech Communication: Speech and Hearing Science presented May 13, 1996

Title: Children with Early Language Delay: A Group Case Study of Outcomes in Intermediate Grades.

Current research in early language development suggests that children who were diagnosed during preschool with expressive language delay would demonstrate difficulties during elementary school years (Scarborough and Dobrich, 1990). This purpose of the present study was to qualitatively describe the outcome of children with a history of early language delay and differing levels of expressive performance (ELD and HELD), as reported by the parents. A questionnaire was developed to determine the children's current age and grade level, past and present reading ability and reading interests, best and worst academic subject, special services and diagnosed disability, speech and language concerns, friendships concerns, and behavioral and motor issues. The study used Developmental Sentence Scoring (Lee, 1974), which determined which children continued to function below the normal 
range at second grade. Once identified, these children were placed into two groups indicating early language delay (ELD) and history of early language delay (HELD). The data was collected from parent interviews and placed into tables for analysis. Case vignettes were developed for each ELD and HELD subject. The suggested trends from the study include: Differences in reading material, literacy related play activities, number of friends, and similar special services received in school. 
CHILDREN WITH EARLY LANGUAGE DELAY: A GROUP CASE STUDY OF OUTCOMES IN INTERMEDIATE GRADES

by

TRACEY ABILD-LANE

A thesis submitted in partial fulfillment of the requirements for the degree of

\author{
MASTER OF SCIENCE \\ IN \\ SPEECH COMMUNICATION: \\ SPEECH AND HEARING SCIENCE
}

Portland State University

1996 


\section{ACKNOWLEDGEMENTS}

I wish to thank Dr. Rhea Paul who has served as my thesis and academic advisor. She has given me support, guidance and expert advice on this project. I also wish to thank Ellen Reuler, who so willingly served on my thesis committee.

For my husband, Steve, whose sense of humor and uncanny ability to make me laugh, helped me keep my sanity during this project.

Lastly, thanks to my mom and dad, Lilli and Orin Abild who have offered support and encouragement during the past two years of graduate school, as well as this project. I am very happy to have spent all that money on longdistance telephone calls, when I didn't want anything except the need to chat! 
TABLE OF CONTENTS

PAGE

ACKNOWLEDGEMENTS . . . . . . . . . . ii

LIST OF TABLES . . . . . . . . . . . . . vi

CHAPTER

I INTRODUCTION AND STATEMENT OF PURPOSE . . . 1

Introduction . $\quad . \quad . \quad . \quad . \quad . \quad . \quad . \quad .1$

Statement of Purpose $\quad$. . . . . . . 2

Definition of Terms . . . . . . . 3

II REVIEW OF THE LITERATURE . . . . . . . 5

Research on Early Language Delay . . . 5

School Age Outcomes in Early Language Delay $\quad .8$

Controversy on Early Language Delay . . . . 10

Qualitative Analysis Procedures . . . . . 12

III METHODS AND PROCEDURES. . . . . . . . . .

Subjects . . . . . . . . . . . 14

Subject Description at Intake:

20 to 30 Months . . . . . . . . . .

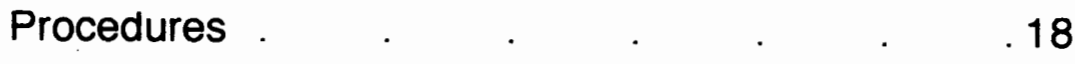


PAGE

Instrumentation $\ldots . .21$

Developmental Sentence Scoring . . . . 21

Interview $\quad . \quad . \quad . \quad . \quad .22$

Reliability of Instrumentation . . . . . 23

DSS Reliability $\quad . \quad . \quad . \quad . \quad .23$

Reliability of DSS for PLDP $\quad . \quad$. $\quad .24$

Reliability of Interview Analysis . . . . 25

Data Analysis . . . . . . . . . 26

VI RESULTS AND DISCUSSION . . . . . . . . 28

ELD Case Vignettes. $\quad . \quad . \quad . \quad .29$

HELD Case Vignettes . . . . . . 32

Results $\quad . \quad . \quad . \quad . \quad . \quad . \quad .34$

ELD Group Trends . $\quad$. $\quad$. $\quad$. 34

HELD Group Trends . . . . . . . . 39

Discussion . . . . . . . . . . . 45

V SUMMARY AND IMPLICATIONS. . . . . . . . 47

Summary $\quad . \quad . \quad . \quad . \quad . \quad . \quad .47$

Implications . $\quad . \quad . \quad . \quad . \quad .49$

Clinical . . . . . . . . . . 49 
PAGE

Research . . . . . . 50

REFERENCES . . . . . . . . . . . . . . . 52

APPENDICES . . . . . . . . . . . . . . . . 55

A QUESTIONAIRES . . . . . . . . . . . . . . . 59

B HUMAN SUBJECT'S APPROVAL . . . . . . . 61

C CODING SHEET . . . . . . . . . . . . . . . . 63

D SUBJECT INFORMATION. . . . . . . . . . . . 68 


\section{LIST OF TABLES}

TABLE

PAGE

1 PLDP Summary of Demographic Data at Intake . . 16

2 Summary of Subject Demographic Data . . . 17

3 Like to Read, Read for Fun, Read Like Peers . . . 34

4 Best Subjects, Worst Subjects . . . . . . . 35

5 Like School, Difficulty in School, Succeeding in School Struggling in School

6 Current Services, Previously Received Services, Type, Diagnosed Disability

7 Speech \& Language Concerns, Friendship Concerns, Ability to Get Along With Others . . . . . . 38

8 Behavioral Problems, Motor Problems . . . . . 39

9 Like to Read, Read for Fun, Read Like Peers . . . 40

10 Best Subjects, Worst Subjects . . . . . . . 41

11 Like School, Difficulty in School, Succeeding in School Struggling in School . . . . . . . 42

12 Current Services, Previously Received Services, Type, Diagnosed Disability

13 Speech \& Language Concerns, Friendship Concerns, Ability to Get Along With Others .

14 Behavioral Problems, Motor Problems. 


\section{CHAPTER I}

\section{INTRODUCTION AND STATEMENT OF PURPOSE}

\section{INTRODUCTION}

When children are identified as having a language delay prior to age three, it is often difficult to predict what the outcomes will be once they reach elementary school. Will they continue to have language deficits and academic difficulties, or will they outgrow their problem? If children persist in having language and academic trouble, what factors play a part in the continued deficits? According to a portion of reports in the literature, a percentage of children who are identified with early language delay often have difficulty later in elementary school. Describing late talking children in later elementary school could provide information regarding which children may need special services, may have social difficulties, learning and/or reading difficulties, and may have continue to show academic deficiency. Knowing what kinds of difficulties the late talking children could have in elementary school, may also help teachers and speech-language pathologists in developing treatment programs for these children early in school.

Due to the fact that academic performance depends on language aptitude, children with specific expressive language delay (SELD) may be at 
risk. Scarborough and Dobrich (1990) have shown academic difficulties in a small group of children with a history of expressive language delay. Although this study is focuses on parent descriptions of children in later elementary school who were identified as late talkers during preschool, more studies involving children with SELD and their outcomes in later elementary school are needed to determine academic, literacy, and social performance.

\section{STATEMENT OF PURPOSE}

The purpose of this study was to describe the academic and social outcome of children identified with a language delay early in preschool. The information obtained was provided from the parents' point of view. Some of the potential long-term problems these children may continue to encounter include: Performance behind that of peers as measured by standardized tests, poor grades, poor performance on achievement tests, poor social skills, and being identified as learning disabled.

\section{The Research Hypothesis}

Since this paper was a descriptive group case study which collected qualitative data, a hypothesis was not tested and parametric statistics were not calculated on the obtained data. However, the research question to be answered was: What do parent reports reveal about the outcomes of children 
in late elementary school, who were diagnosed with specific expressive language delay in preschool?

\section{DEFINITION OF TERMS}

Portland Lanquage Development Project (PLDP): A longitudinal study studying the outcomes of late talking children.

Learning Disability: Defined by Catts and Kamhi (1989) as a discrepancy between intellectual ability and one or more areas of language development and/or academic achievement.

Late Talkers (LT): Subjects categorized by the PLDP to have vocabularies of less than fifty different words between the ages of 20 and 34 months, in accordance with the Rescorla (1989) Language Development Survey (LDS).

Slow Expressive Lanquage Delay (SELD): Subjects categorized by the PLDP to have vocabularies of less than 50 different words at the age of 20 to 34 months, in accordance with the Rescorla (1989) Language Development Survey (LDS).

Specific Language Impairment (SLI): Considered to be relatively specific failure of normal language functions, in the absence of any neurological damage (Tallal, 1988).

Receptive/Expressive Language Delay: Subjects categorized by the PLDP to have vocabularies of less than 50 different words at 20 to 34 months 
of age, according to the LDS; and a score one standard deviation or more below the mean on the comprehension skills section of the Reynell Developmental Language Scales (RDLS).

Reynell Developmental Scales (RDLS): Standardized assessment, used to measure the development of verbal comprehension at intake in the PLDP (Reynell, 1983).

Developmental Sentence Scoring (DSS): Standardized measure of syntactical development in children, based on a spontaneous language sample (Lee, 1974). 


\section{CHAPTER ॥}

\section{REVIEW OF THE LITERATURE}

Over the past several years, there has been an increased interest in children who have specific expressive language delay (SELD). Some of the recent research has investigated how children with SELD begin to develop language. Several studies report that $40 \%-60 \%$ of children with SELD have ongoing difficulties with language development (Aram and Nation, 1980; Rescorla and Schwartz, 1990). Requirements of school curriculum necessitate higher level language skills and literacy skills which are language based. This may lead to increased difficulties in a child with expressive language problems or a history of problems. This study focuses on parents' perceptions of their children's academic abilities and overall functioning, eight years after they were identified with early language delay. The study reports information on trends, patterns, and behaviors observed across the families participating in the study.

\section{RESEARCH ON EARLY LANGUAGE DELAY}

According to Paul (1991), very little is known about the prognosis for two year old children with delayed language abilities. Past data have 
suggested that children with learning disabilities often have a history of slow language growth (Catts \& Kamhi, 1986; Maxwell \& Wallach, 1984; Weiner, 1985). It is also known that older preschoolers with language delays are at a substantial risk for long-term language, academic, and social difficulty (Aram \& Nation, 1980; Hall \& Tomblin, 1978; Paul and Cohen, 1984).

Schery's (1985) longitudinal study of children with language disorders, found that several factors contributed most to the prediction outcome of children with language delays. The factors which contributed most to improvement included how young the child was at intake, the child's nonverbal IQ, the social/emotional status, the socioeconomic status, and the family history of language delay. Leonard (1989) suggests in his study on children with specific language impairment that long-term language limitations can be very extensive. For example, Leonard (1989) states that follow-up studies on children under age 10, who were previously identified during preschool or early elementary school with specific language impairment (SLI), Show that over $60 \%$ continue to display language limitations. Rescorla (1991) suggests that when children are identified with language delay during preschool, they are at risk for later educational and mental health problems, and learning disabilities later on in school.

Rescorla and Schwartz (1990) conducted a follow-up study on 25 male toddlers with slow expressive language delay (SELD) who were originally diagnosed in the 24 to 31 month age group. At follow-up, eight months later, 
approximately $50 \%$ of the 25 boys continued to display poor expressive language. According to Thal and Tobias (1994), significant numbers of toddlers who have been identified as language delayed between the ages of 18 and 32 months remain delayed. These toddlers are also at higher risk for more language disorders, social emotional problems, and learning disabilities (Fischel, Whitehurst, \& Conners, 1987; Paul, Spangle-Looney, \& Dahm, 1991; Rescorla \& Schwartz, 1990; Scarborough \& Dobrich, 1990; Thal, Tobias \& Morrison, 1991; Thal \& Tobias, 1994). Other research has shown that many students identified early in preschool with somewhat severe language problems, will have subsequent difficulties learning to read (Catts and Kamhi, 1989). Even though other longitudinal studies have indicated that $50 \%$ of children who are slow in expressive language development appear to get better in language performance by age 3, learning disorders in reading and writing may emerge in these children as they are tracked over the years (Paul, Spangle Looney, \& Dahm, 1991; Scarborough \& Dobrich, 1990).

Paul (1993) conducted a study on the developmental patterns of change during the preschool years in children with specific expressive language delay (SELD). Paul found that SELD children were performing within the normal range in receptive skills and expressive vocabulary by age 3. At 3 years of age, $74 \%$ of SELD children continued to score below normal in expressive syntax, articulation, or both, even though the children experienced vocabulary growth. At 4 years of age, the number of children who 
scored below the normal range in expressive syntax, articulation, or both, had decreased to $67 \%$.

Since early language delay can have significant repercussions on later educational achievement, it is important to know the outcomes of children with early language delay since many children may also be at risk for long-term language and other related problems. For these reasons, it is important to identify early which children will continue to experience language deficits.

School Age Outcomes in Early Language Delay

Scarborough and Dobrich (1990) conducted a longitudinal study focusing on the development of four children who were identified with early language delay (ELD) between the ages of $21 / 2$ and 5 years. All the children had deficiencies in expressive syntax, phonology, and semantics. By age 5, these children were found to have normal or near normal language skills. Scarborough and Dobrich (1990) call this "Illusory Recovery," because, by age 8 , three of the four ELD children were found to have severe reading disabilities. The authors suggest that this outcome is directly attributed to the early language delay the children experienced (Scarborough and Dobrich, 1990).

Bishop and Edmundson (1987) conducted a study on predicting language outcomes of children with phonological, syntactical, morphological, and semantic delays. They found that they were able to predict prognosis of 
persistent impairment for individual children with or without a language impairment with $90 \%$ accuracy on the basis of language testing completed at 4 years of age. Silva, Williams, and McGee (1987) conducted a longitudinal study on children who were identified at age 3 with developmental language delay, then were followed up at age 7,9 , and 11 . They found that by age 11 , children who were delayed in either verbal comprehension or expression only, had mean reading scores similar to those of children 2 years younger (Silva, Williams, and McGee, 1987). Bishop and Adams (1990) found that the best linguistic predictors of reading achievement at age 8 1/2 for children diagnosed at age 4 with language impairment were mean length of utterance and general syntactic measures.

A study was conducted by Griffiths (as cited in Haynes and Naidoo, 1991) on 49 children between 1 and 7 years after leaving a school for speech and language impairment. She found that $70 \%$ of them had speech and language within normal limits. However, most of the children had considerable educational problems, particularly with reading (Haynes and Naidoo, 1991).

Whitehurst and Fischel (1994) conducted a review of studies of children with SELD, which includes three ongoing longitudinal studies. They reported that the three longitudinal studies were comparable in finding that specific expressive language delay is a risk factor for later language related problems and not a disorder. As reported in the three longitudinal studies, the majority 
of the children moved into the normal range of language performance by age 5. Also, the three longitudinal studies' subjects displayed normal expressive vocabularies throughout the follow-up even though small expressive vocabulary was the primary symptom. Through analysis of the three longitudinal studies, Whitehurst and Fischel (1994) resolved that SELD can be considered a risk factor in children under age five. After 5 years, if the children continue to have expressive language delay the risk factor seems to increase.

\section{Controversy on Early Language Delay}

Whitehurst and Fischel (1994) suggest that some cases of delays in language development are secondary to conditions such as mental retardation, brain damage or hearing loss. In other cases, language impairments occur in conjunction with associated problems such as hyperactivity and attention deficits, or in isolation from other developmental problems. They suggest that distinctions between secondary language delay and specific language delay be incorporated into diagnostic considerations because of implications for prognosis and treatment.

When taking familial aspects into consideration, Whitehurst et al. (1991) report that there were no differences in family history of speech, language and school problems in sixty-two 2 year olds with specific expressive delay when compared with 55 normally developing children. They also suggest that family history was not a predictor of later language development. These results are 
in direct conflict with the findings of Paul (1991), who suggests that a family history of language, speech or learning problems was three to four times more frequent in 2 year olds with specific language delay than in a normally developing control group, and Bishop and Edmundson (1986), who reported that $46 \%$ of 56 language impaired 4 year olds had blood relatives with a history of language impairment, stuttering or reading disorders. Whitehurst and Fischel (1994) suggest that the reason for the conflict is that Whitehurst et. al. limited their sample to children specific expressive delay, where the other studies included children with receptive-expressive delays and/or children with secondary delays.

Bishop and Adams (1990) investigated literacy skills of eighty-three 8 $1 / 2$ year olds whose language development had been delayed at 4 years of age; these children were also investigated at age $51 / 2$ by Bishop and Edmundson (1987). Bishop and Adams (1990) report that $44 \%$ of the 4 year olds with specific language delay had no measurable language impairment by 5 1/2 years of age, which was compatible with the catch-up behavior described by Paul, et al. (1993), Rescorla (1993), Scarborough and Dobrich (1990), and Whitehurst et al. (1992). At the $81 / 2$ year old age level, Whitehurst and Fischel (1994) recoded Bishop and Adams' (1990) data and identified children with reading problems based on reading performance of more than 1 standard deviation below the mean. Using this criterion, Whitehurst and Fischel (1994) found that those who experienced the highest 
risk of reading problems at age $81 / 2$ were the children who had secondary language delay at age 4 . These children did not catch up in language at age $51 / 2,63 \%$ had difficulty in reading accuracy, and $81 \%$ had problems in reading comprehension at age $81 / 2$. In addition, children who were delayed in reading at $81 / 2$ years of age also continued to be impaired in expressive and receptive language. In opposition to Scarborough and Dobrich (1990), Whitehurst and Fischel (1994) found there was not an "Illusory recovery" among the children. Those who were reading impaired at $81 / 2$ years were also language impaired at age $4,51 / 2$, and $81 / 2$ years.

Based on the findings in the literature, there is a need to describe the long-term outcome of the children who are slow in expressive language development as preschoolers. The present study will describe characteristics of children who were identified as late talkers during the early preschool period and continue to have expressive language lags at school age. It is hoped that this study will provide some information as to which factors are common among late talking children with persistent difficulties.

\section{QUALITATIVE ANALYSIS PROCEDURES}

The current study employed qualitative research methods, which uses the data collection techniques of participant observation and/or intensive interviewing, and data analysis that are nonquantitative (Lofland and Lofland, 1984). The qualitative goal of research is to isolate and define categories 
during the process of research (McCracken, 1988). Qualitative research methods have become increasingly important modes of inquiry for the social sciences (Marshall and Rossman, 1989). Qualitative research begins with observation in the natural setting. Theories about events are developed as ways of reducing ambiguity and explaining paradox. These theories help bring questions, the phenomenon or the problematic issue into focus which helps to frame a focused research question (Marshall and Rossman, 1989).

Qualitative methods are appropriate for exploratory studies where the categories or variables of interest are not yet well-defined. This study makes use of qualitative methods as well as quantitative descriptions methods, since it is not yet known what variables will be used to describe children with persistent language delays.

\section{SUMMARY}

Several studies have shown that children with early language delay continue to problems as they grow. The current literature shows differing points of view regarding the effects of early language delay on elementary school age children. The literature shows that more research is needed to describe the outcome when children move from learning to read and start reading to learn. This study will provide information on the outcome of children during intermediate grades, with history of expressive language delay and expressive language delay. 
CHAPTER III

\section{METHODS AND PROCEDURES}

\section{SUBJECTS}

The subjects in this study came from the Portiand Language Development Project (PLDP), a longitudinal study of toddlers with early language delay, which began in 1987. Subjects for the current study were those who were identified as late talkers as toddlers and continued to score below the normal range on Lee's (1974) Developmental Sentence Scoring (DSS) in the second grade. Information and history was retrieved from existing files of the PLDP's participants.

\section{SUBJECT DESCRIPTION AT INTAKE: 20-34 Months}

The children were recruited from local pediatric clinics and through newspaper advertisements when they were between 20 and 34 months of age. Two groups were identified at intake: Normal and late talkers (LT). The subjects were considered normal if parents reported more than 50 different words on the Language Development Survey (LDS) (Rescorla, 1989), which is a checklist consisting of 300 of the most common words used by children. The subjects were considered LT if they used fewer than 50 different words on 
the LDS, or if they did not use two-word combinations in their speech. All subjects completed and passed a hearing screening, scored IQs on the Bayley Scales of Infant Development (Bayley, 1969) of 85 or above, passed a screening for neurological disorders and autism and had no known physical handicaps.

Table 1 shows the demographic information of subjects at intake. The table includes the number of subjects, mean age, socioeconomic status (SES), gender, and race.

For this study, subjects from the original group of late talkers (LT) who continued to have delays in expressive language in second grade, as indexed by a score below the 10th percentile on the DSS, were followed. A contrast group of children from the PLDP, who were LT at intake but perform above the 10th percentile on the DSS in second grade, were chosen to match the children with continuing delays, on the basis of sex and SES.

Table 2 shows the demographic information of the groups used for this study. The table includes the number of subjects, mean age at intake, mean age now, mean SES, gender ratio, mean DSS score, and mean grade level. 


\section{TABLE}

PLDP GROUP DEMOGRAPHIC INFORMATION AT INTAKE IN 1987

\begin{tabular}{lcccccc}
\hline Group & $n$ & Mean Age at Intake (SD) & Mean SESa & Gender & Race \\
\hline Normal & 27 & 25.1 mo. & $(4.6)$ & 2.6 & $56 \%$ male & $85 \%$ Caucasian \\
SELD & 32 & 25.3 mo. & $(4.1)$ & 2.6 & $80 \%$ male & $93 \%$ Caucasian \\
\hline
\end{tabular}

a Based on a two factor index based on Myers and Bean (1968) where 1 is the highest and 5 is the lowest SES rating. 
TABLE \|

SUBJECT DEMOGRAPHIC INFORMATION

\begin{tabular}{|c|c|c|c|c|c|c|c|}
\hline Group & $n$ & $\begin{array}{l}\text { Mean Age } \\
\text { at Intake } \\
\text { (mo.) }\end{array}$ & $\begin{array}{l}\text { Mean Age } \\
\text { at } 2 \text { nd Gr. } \\
\text { (mo.) }\end{array}$ & Gender & SESa & $\begin{array}{l}\text { Mean DSS Score } \\
\text { at Second Grade }\end{array}$ & $\begin{array}{l}\text { Mean Present } \\
\text { Grade Level }\end{array}$ \\
\hline ELD & 5 & 27 & 97.2 & $60 \%$ male & 3.2 & 7.046 & 5.0 \\
\hline HELD & 4 & 28.5 & 95.75 & $75 \%$ male & 3.2 & 10.180 & 5.25 \\
\hline
\end{tabular}

a Based on a two factor index based on Myers and Bean (1968) where 1 is the highest and 5 is the lowest SES rating. 


\section{PROCEDURES}

\section{Follow Up at Second Grade}

Developmental Sentence Scoring (DSS) was used as an index of expressive syntax and language abilities to age 7. Spontaneous speech samples were obtained at the second grade follow up for each subject through an interview format (Evans and Craig, 1992). The samples were analyzed using Lee's (1974) guidelines for DSS scoring. According to Lee (1974), language samples should be tape recorded, and attempts should be made to elicit complete sentences and high-level grammatical forms. One hundred utterances is the accepted standard for DSS since it is a realistic number to expect from a child. Anything less than 100 utterances may still be used for analysis, but should be noted that it is only an estimate of the child's grammatical development. Once 100 utterances have been obtained, 50 complete sentences containing a subject and a predicate are selected for DSS analysis.

For the PLDP, subjects were seen by graduate research assistants for a follow-up evaluation during second grade. Fifteen minute speech samples were collected through an interview which followed Evans and Craig's (1992) specifications, and were audiotaped for reference. The interviewer, who was a graduate assistant working for the PLDP, asked the child to talk about his/her family members, school experiences, and free-time activities. Once the child 
had chosen a topic, the interviewer let the child dictate the direction the conversation would take.

A transcription of the tape was made by the graduate student present at the time of taping. DSS (Lee, 1974) was then used to analyze the spontaneous speech samples of each subject. This was done by a trained graduate assistant in accordance with the DSS guidelines.

Normal language performance was indicated if the child scored at or above the 10th percentile for age 7 on the DSS, a score of 8.11 . The mean score for the normal group at second grade was 10.54. The LT group was divided into two subgroups based on their DSS score at age 7: Children with history of expressive language delay (HELD) and children with chronic expressive language delay (ELD). The HELD group was comprised of children who were originally identified as $L T$, as documented by a vocabulary of less than 50 words between 20 and 34 months of age, and DSS scores of above 8.11 at second grade. The mean DSS score for the HELD group at second grade was 10.11. The ELD group was also comprised of children originally diagnosed as LT, who continued to show deficits in expressive syntax as documented by DSS scores below 8.11 in second grade. The mean DSS score of the ELD group at second grade was 7.05. Of the 32 LT children, only five were placed in the ELD group as a result of their DSS scores. All of these five children were included in the present study. The remaining 27 were 
placed in the HELD group. Four of these children were also included in the present study.

\section{Present Study}

For the present study, the DSS results from the 1990 follow up were used to identify subjects. The subject groups included all members of the ELD group, who were then contrasted with matched subjects from the HELD group.

A questionnaire (Appendix A) was used during a parent interview which disclosed how the children were currently functioning. The parents were contacted by phone and the interview was set up at their convenience. The interview was conducted in the parent's home and was audiotaped. If it was not possible to conduct the interview in the home, it was conducted over the phone and audiotaped as well. The questions were open-ended and included the parent's opinion of the following:

1. The parent's opinion of their child's academic and language ability.

2. What the parents feel their child's strengths and weaknesses are in school.

3. If their child has a diagnosed disability.

4. Their child's history of speech-language treatment.

5. If their child receives special education services, and if so, what type of services. 
6. What their child likes to read.

7. How their child likes to play.

8. Whether the parents have any concerns regarding their child's speech and language learning.

The information was described from the parents point of view.

The application for human subjects approval was submitted and granted by the Portland State University Human Subjects Review Committee to conduct the interviews (Appendix B).

\section{INSTRUMENTATION}

\section{Developmental Sentence Scoring}

This study used the Developmental Sentence Score as an index of language performance and was used to determine language functioning at the second grade follow up. The DSS is a standardized measure which assesses the syntactical structures found in the speech samples by assigning weighted scores to complete sentences. According to DSS protocol, a complete sentence contains a noun and a verb in subject-predicate alignment. Fifty complete sentences are required for analysis. The structures examined include indefinite pronouns, personal pronouns, main verbs, secondary verbs, negative, conjunctions, interrogative reversals, and wh-questions (Lee, 1974). The DSS assigns the sentence structures scores in these categories which 
are based on eight developmental levels. Points for the sentence structures are compiled, added, and divided by 50 (the total number of utterances), in order to obtain the Developmental Sentence Score. Using the scores obtained on the DSS allows for identification of language delay.

The DSS has been shown to have high reliability and validity in measuring the syntax and morphology usage in children aged 2 years, to 6 years, 11 months. As the scores increase with each age level, this indicates high internal consistency, and high validity which is positively correlated with overall DSS scores.

interview

For the present study, an open-ended interview format was used for obtaining information from the subject's parents. The format was an asset to obtaining the data, as the researcher was allowed to follow up on what the respondent said. The researcher was also allowed to ask questions that clarified what was not understood. The interview consisted of open-ended questions which established the territory to be explored while allowing the participant to take any direction he or she wishes. The answers to the questions were recorded by hand, as well as tape recorded for future reference. The data obtained from the interviews was presented as straightforward answers, such as the age when the subjects began reading, and their present ages and grade levels using means and standard 
deviations. A coding sheet (Appendix C) was used to record the straightforward answers provided by the parents. The supplementary information from the open-ended responses was be described qualitatively and contrasted between the two groups.

\section{Audiotape Equipment}

A Sony ECM-144 Electret condenser lavalier microphone and a Sony Dictator/Transcriber BM-88 with Sony dictation cassette DC-30N, were used to record the fifteen minute DSS speech samples at the second grade follow up. The equipment was turned on after the instructions were given.

For the present study, the interviews were recorded on a Sony Microcassette-Corder M-717V with Sony Microcassette MC60 cassette tapes. After the instructions were given, the equipment was turned on.

\section{RELIABILITY OF INSTRUMENTATION}

\section{DSS Reliability}

The DSS was chosen as the method of identifying expressive language abilities at the second grade follow up, for its high validity and reliability measures. The DSS analysis was standardized on 200 subjects, and can be used to score expressive language abilities of children between the ages of 2 years, to 6 years, 11 months. Twenty male and female children make up each 
three month age group, which allows for adequate power in the sample size. Normative data consists of age equivalent and percentile ranks.

DSS validity was established using multivariate analysis of variance and univariate analysis of mean developmental scores within the DSS categories. It was determined that as age levels increased, the scores which measured spontaneous syntax and morphology usage increased with each age level. This indicates that grammatical development was being measured. The validity of the individual grammatical categories was positively correlated with the overall DSS scores using Pearson product-moment correlations.

To support the validity measures, reliability was also established. Internal consistency of the DSS was calculated by Cronbach's Alpha Correlation Coefficient to be .71 . The reliability coefficient increased by age level indicating increasing internal consistency for the DSS with increasing subject age. Across subjects, the internal consistency was measured using the Spearman-Brow's Split-Half Reliability method. This measure also showed a progressive increase in reliability with the increasing age of the subjects. A Spearman-Brow coefficient of .73 is indicative of good stability of scoring within the subjects. Interjudge reliability did not show significant differences between the DSS scores of two different judges.

\section{Reliability of DSS for PLDP}


Graduate assistants for the PLDP were trained to perform reliability measures on the language samples obtained at the second grade follow up. Eleven percent of the language samples used for DSS analysis were randomly selected and scored independently by a second graduate assistant. Transcription reliability of word by word agreement was performed on $11 \%$ of the subjects at $94 \%$ accuracy. Sentence choice reliability was calculated at $90 \%$ on $8 \%$ of the subjects. Point by point reliability was calculated on $14 \%$ of the language samples at $92 \%$ accuracy. Total DSS reliability was determined to be $97 \%$ on eleven percent of the subjects. These results strongly support its effectiveness as an objective measure of syntactic development in children.

\section{Reliability of Interview Analysis}

To determine reliability for the interview analysis in the present study, LeCompte and Goetz (1982) suggest that reliability in qualitative research is dependent on the outcome of both external and internal design problems. External reliability addresses whether independent researchers would generate the same conclusions in the same or similar settings. Internal reliability refers to the degree to which other researchers, given a set of previously generated constructs, would match them with data in the same way as did the original researcher. LeCompte and Goetz (1982) suggest that since qualitative research occurs in a natural setting and often reports the processes of change, these unique situations cannot be reconstructed 
precisely. Human behavior is never static, so no study can replicated exactly, regardless of the methods and designs employed. Therefore even the most exact replication of research methods fail to produce identical results in qualitative research.

In order to facilitate replication of qualitative research, LeCompte and Goetz (1982) suggest that the researcher must create categories for coding in order to analyze the results; it is essential to the process of organizing the naturally occurring behavior into units. These units of analysis should be identified clearly regarding where they begin and end, and when appropriate, which variables form the framework for data collection and analysis. Therefore, replicability is impossible without precise identification and thorough description of the strategies used to collect the data (LeCompte and Goetz, 1982).

For the current study, the researcher did not know whether the subjects belonged to the ELD group or the HELD group. This facilitated removal of researcher bias during the interviews and presentation of data. In addition, coding procedures for the interview data were taught to a second year graduate student who reanalyzed a $10 \%$ sample of the interview questions. Agreement between the two judges were assessed for reliability using a pointto-point method and was determined to be $97 \%$. 


\section{DATA ANALYSIS}

Developmental Sentence Scores (Lee, 1974) obtained at the second grade follow up, were taken from the files of the PLDP for use in the present study. Answers to interview questions were reported in a straightforward and qualitative manner. Results were recorded onto the coding sheet which was specifically developed for this study. Once the information was obtained from the interviews and placed in the tables, the subject groups were identified to the researcher. This helped to facilitate comparison between the groups. Short paragraphs describing each of the subjects precedes the reported results to the interview questions. The straightforward answers, such as the age when the children began reading, and the current ages and grade levels for the ELD group, were compared with those same answers for the HELD group using means and standard deviations. The additional information obtained from the open-ended responses from the ELD group was described qualitatively and compared with the responses from the HELD group. 


\section{CHAPTER IV \\ RESULTS AND DISCUSSION}

The purpose of this study was to describe the outcome of five ELD children who continue to retain their language deficiencies at school age. All reported information was reported by the parents. This information was then compared to that reported by the parents of four HELD children, who previously had language deficiencies, but performed within the normal range by second grade. Results from Lee's Developmental Sentence Scoring (DSS) (1974) were used to determine the child's expressive ability, and identify which children were continuing to function as delayed, as well as which children were functioning normally at second grade.

The research question was asked: What do parent reports reveal about the outcomes of children in late elementary school, who were diagnosed with specific expressive language delay in preschool?

The following are case vignettes for each subject based on the parent information obtained in the interview: 


\section{ELD Case Vignettes}

Subject 015 is a male, aged 11 years 9 months and is in 5 th grade. He was able to read at age 5 1/2 years of age. Favorite reading material includes "Goosebumps", comic books, and science fiction stories. His parents view him as succeeding in school because he puts effort into his school work. However, parents stated that school is also difficult due to trouble with math, and he struggles with school because he is not very competent socially. He has received special services in special education and speech-language pathology. Parents wish there was a better balance between the pull out model and the classroom in regards to services. This child has a diagnosed disability of autism which the family has protected him from, and parents consider him to be a normal kid. There are parental concerns for speech and language learning due to an inability to express himself adequately, and also for friendships due to difficulty with communication. Parents have stated that this child has one best friend, and they enjoy playing video games together. This child has motor difficulties involving coordination.

Subject 019 is a female, aged 11 years, 9 months, and is in sixth grade. She began reading at 5 years of age. Favorite reading material includes "American Girl", magazines, and young children's books. Her parents indicated that school is difficult and as a result, receives a modified teaching program. She currently receives services of special education, which parents stated provides help with learning strategies, as well as redundancy to help 
her understand concepts. Although she does not have a current disability, her parents feel she is learning disabled. There are parental concerns for friendships and was described as a loner with poor social skills. Parents also stated that she has more acquaintances than friends. Parents said she has behavioral fits of rage, and also takes antidepressants.

Subject 093 is a male, aged 10 years, 11 months, and is in fifth grade. He began reading at $71 / 2$ years of age. Favorite reading material includes "Box Car Children", "Goosebumps", and comic books. His parents indicated that he is struggling in school because he cannot follow directions, does not realize he missed something auditory, and becomes frustrated easily. He is viewed as succeeding in school because parents indicate he performs better academically than an older sibling. He has previously received speechlanguage pathology services and has a current diagnosis of learning disabled. Parents stated he was frustrated with the pull out model, but emerged as a leader and enjoyed helping the other children in speech class. Parents stated he has several friends and they enjoy playing basketball, baseball, football, and hockey together. He also has some motor difficulties involving coordination, but parents stated involvement with sports has helped.

Subject 097 is a male, aged 10 years, 8 months, and is in fourth grade. Parents stated this child is still not able to read on his own. Favorite reading material includes comic books. School is also difficult due to trouble with reading. He is viewed as succeeding in school because his is very social and 
has a positive attitude. He struggles with school because of reading difficulties, which prevents him from going to the library with his the rest of his class; at that time, he attends special education class. He currently receives special education services and carries a diagnosis of learning disabled. Parents stated the services are beneficial because he gets extra one on one attention. Parents feel his disability does not allow him to experience school the same way that peers do, and he sees what he's missing out on. However, parents did say that the disability has brought the family closer together and taught older siblings not to be prejudiced against people with disabilities. He is described as having many friends, they enjoy participating in cub scouts, and collecting trading cards together.

Subject 101 is a female, aged 10 years, 9 months, and is in fifth grade. She began reading at 5 years of age. Favorite reading material includes "Baby-sitter's Club", "Goosebumps", "American Girl", and comic books. Parents stated that school is difficult for her due to trouble understanding math theory; she is struggling in school for the same reasons. In addition, parents view her as succeeding in school because she tries her best. Parents are concerned that the class keeps moving ahead, and she is getting left behind in math. She has one best friend, and together they enjoy collecting dolls, making crafts, and rollerblading. This child also has motor problems involving coordination. 


\section{HELD Case Vignettes}

Subject 012 is a female, aged 11 years, 0 months, and is in 5 th grade. She began reading at 6 years of age. Favorite reading material includes "Goosebumps", "Baby-sitter's Club", and "Chicken Soups with Rice". Parents indicated school is difficult because she is heavy set and is teased by peers. She is succeeding in school because she is very social and has wellgrounded friends. She is also struggling with staying on task and working independently. She has previously received special services in speechlanguage pathology. She is described as having many friends, and they enjoy playing basketball, reading books, and writing plays together.

Subject 085 is a male, aged 11 years, 0 months, and is in fifth grade. He began reading at $81 / 2$ years of age. Favorite reading material includes "Goosebumps" and car magazines. He does not like school. Parents indicate school is difficult because the teacher has a fast teaching pace which makes keeping up with the class difficult. The parents also state that he is not succeeding in school because he receives poor grades, does not seek out help, and gives up easily. He is struggling with school becasue he does not understand assignments and cannot remember concepts. He has previously received special education services. His parents wish he was served at the present time because he needs help developing learning strategies. He previously had a diagnosis of learning disabled, but did not qualify for services 
this academic year. There are parental concerns for speech and language learning due to difficulty with comprehension in reading and auditory processing. He is described as having several friends, and they enjoy biking and rollerblading together. Parents also indicated some behavior problems involving crying due to frustration.

Subject 092 is a male, aged 11 years, 8 months, and is in sixth grade. Favorite reading material includes "National Geographic" for kids, and "Redwall Series". Parents stated school is difficult for him due to trouble staying on task and misunderstanding assignments. He is also seen as succeeding in school because was identified as talented and gifted (TAG). He has previously received speech-language pathology services. Parents stated that they wish he could have received services during the summer months. There are parental concerns regarding friendships. Parents describe their child as having very few friends at school, but has a pen pal he writes to.

Subject 094 is a male, aged 11 years, 6 months, and is in fifth grade. Favorite reading material includes "Goosebumps" and Nintendo magazines. He is succeeding in school because he was tested for TAG, although he did not qualify. Currently, he is in an enriched program for accelerated students. School is difficult for him because he does ' $C$ ' work in enriched subjects, becomes frustrated with ' $C$ ' grades, and also has a hard time trying to keep up with the schoolwork. He is described as having many friends, and they enjoy playing Nintendo and basketball, football, and baseball together. 
RESULTS

\section{ELD Group Trends}

The ELD group had an average age of 11 years, 2 months with a standard deviation of 6.48 months. The average age the ELD group began reading independently was 6 years, 11 months with a standard deviation of 27.44 months. Most of the children like to read and most read for fun outside of school. Most were reported to read similarly to their peers, but there was one child who does not. This information is presented in Table 3.

\section{TABLE 3}

LIKE TO READ

READ FOR FUN

READ LIKE PEERS

Subject \# Like to Read Read for Fun Read Like Peers

015

019

093

097

101 yes

no

yes

no

yes yes

no

yes

yes

yes yes

yes

yes

no

yes

Parents considered the best subjects in school to be math, reading, writing, language arts, social studies, art, science, computers and history. 
Worst subjects included spelling, reading, and math. This information is presented in Table 4.

\section{TABLE 4}

\section{BEST SUBJECTS}

WORST SUBJECTS

\begin{tabular}{|c|c|c|}
\hline Subject \# & Best Subject & Worst Subject \\
\hline 015 & $\begin{array}{l}\text { Reading, English, } \\
\text { Spelling, Social Studies }\end{array}$ & Math \\
\hline 019 & Art, Computers & Math \\
\hline 093 & $\begin{array}{l}\text { Language Arts, Science } \\
\text { History, Art }\end{array}$ & Math \\
\hline $\begin{array}{l}097 \\
101\end{array}$ & $\begin{array}{l}\text { Math, Art } \\
\text { Writing, Reading }\end{array}$ & $\begin{array}{l}\text { Reading } \\
\text { Math }\end{array}$ \\
\hline
\end{tabular}

All of the children like school. Parents reported that most of the children are having difficulty with school, most are reported to be struggling with school, and all are viewed as succeeding in school. This is presented in Table 5. 
TABLE 5

LIKE SCHOOL

DIFFICULTY IN SCHOOL

SUCCEEDING IN SCHOOL

STRUGGLING IN SCHOOL

Subject \# Like School in School $\begin{gathered}\text { Difficulty } \\ \text { in School in School }\end{gathered}$

$\begin{array}{lllll}015 & \text { yes } & \text { yes } & \text { yes } & \text { yes } \\ 019 & \text { no } & \text { yes } & \text { yes } & \text { no } \\ 093 & \text { yes } & \text { no } & \text { yes } & \text { yes } \\ 097 & \text { yes } & \text { yes } & \text { yes } & \text { yes } \\ 101 & \text { yes } & \text { yes } & \text { yes } & \text { yes }\end{array}$

Most are receiving special services at this time, and most have previously received services in school. Services received included speech language pathology and special education. Most have a diagnosed disability; one with autism and two are learning disabled. This is presented in Table 6. 
TABLE 6

CURRENT SERVICES

PREVIOUSLY RECEIVED SERVICES

TYPE

DIAGNOSED DISABILITY

\begin{tabular}{lllll} 
Subject \# & $\begin{array}{c}\text { Current } \\
\text { Services }\end{array}$ & $\begin{array}{c}\text { Previous } \\
\text { Services }\end{array}$ & Type & $\begin{array}{c}\text { Diagnosed } \\
\text { Disability }\end{array}$ \\
\cline { 5 - 6 } 015 & yes & yes & Spec. Ed/SLP & Autism \\
019 & yes & yes & Spec. Ed & n/a \\
093 & no & yes & SLP & LD \\
097 & yes & yes & Spec. Ed. & LD \\
101 & no & no & n/a & n/a
\end{tabular}

Most of the group did not list speech and language learning as a concern; however, one parent is concerned. In addition, friendships are not a concern for most of the group; however, one parent is concerned. All of the children were reported to be able to get along with others. This is presented in Table 7. 


\begin{tabular}{|c|c|c|c|}
\hline \multicolumn{4}{|c|}{ TABLE 7} \\
\hline \multicolumn{4}{|c|}{$\begin{array}{l}\text { SPEECH \& LANGUAGE CONCERNS } \\
\text { FRIENDSHIP CONCERNS } \\
\text { ABILITY TO GET ALONG WITHOTHERS }\end{array}$} \\
\hline Subject \# & $\begin{array}{c}\text { Speech/Language } \\
\text { Concerns }\end{array}$ & $\begin{array}{l}\text { Friendship } \\
\text { Concerns }\end{array}$ & $\begin{array}{c}\text { Ability to Get } \\
\text { Along with Others }\end{array}$ \\
\hline 097 & no & no & yes \\
\hline 101 & no & no & yes \\
\hline 019 & no & yes & yes \\
\hline 015 & yes & no & yes \\
\hline 093 & no & no & yes \\
\hline
\end{tabular}

Most of the children did not have behavioral issues; however, one child did display behavioral problems. Most of the children were reported to have motor issues involving coordination. This is presented in Table 8. 


\section{TABLE 8}

\section{BEHAVIORAL PROBLEMS}

MOTOR PROBLEMS

\begin{tabular}{|c|c|c|}
\hline Subject \# & Behavior Problems & Motor Problems \\
\hline 015 & no & yes \\
\hline 019 & yes & no \\
\hline 093 & no & yes \\
\hline 097 & no & no \\
\hline 101 & no & yes \\
\hline
\end{tabular}

\section{HELD Group Trends}

The average age for the HELD group was 11 years, 3 months with a standard deviation of 4.12 months. The average age the HELD group began reading independently was 6 years, 7 months with a standard deviation of 15.0 months. Most like to read, all are reported to read similarly to their peers and all are reported to read for fun outside of school. This information is presented in Table 9. 


\begin{tabular}{|c|c|c|c|}
\hline & $\begin{array}{r}\mathrm{L} \\
\mathrm{RE} \\
\mathrm{REA}\end{array}$ & $\begin{array}{l}\text { TABLE } 9 \\
\text { ETO READ } \\
\text { D FOR FUN } \\
\text { LIKE PEERS }\end{array}$ & . \\
\hline Subject \# & Like to Read & Read for Fun & Read Like Peers \\
\hline 012 & yes & yes & yes \\
\hline 085 & yes & yes & yes \\
\hline 092 & no & yes & yes \\
\hline 094 & yes & yes & yes \\
\hline
\end{tabular}

The parents reported the best subjects were math, reading, social studies, art and spelling. Worst subjects for group included spelling, math, science, reading, and social studies. This is presented in Table 10. 


\section{TABLE 10}

BEST SUBJECTS

WORST SUBJECTS

\begin{tabular}{lll} 
Subject \# & Best Subject & Worst Subject \\
\cline { 2 - 3 } 012 & Math & Spelling \\
085 & Art, Spelling & Math, Reading, Social \\
& & Studies \\
092 & Math & Spelling \\
094 & Reading, Spelling & Math, Science \\
& English, Social Studies &
\end{tabular}

Most of the children are reported to like school. All of the children were reported to have difficulty in school. Most of the children are seen as succeeding in school. Only half of the children are reported to be struggling with school. This is presented in Table 11. 


\section{TABLE 11}

LIKE SCHOOL

DIFFICULTY IN SCHOOL

SUCCEEDING IN SCHOOL

STRUGGLING IN SCHOOL

\section{Difficulty Succeeding Struggling \\ Subject \# Like School in School in School in School}

$\begin{array}{lllll}012 & \text { yes } & \text { yes } & \text { yes } & \text { yes } \\ 085 & \text { no } & \text { yes } & \text { no } & \text { yes } \\ 092 & \text { yes } & \text { yes } & \text { yes } & \text { no } \\ 094 & \text { yes } & \text { yes } & \text { yes } & \text { no }\end{array}$

None of the children are receiving special services at this time. Most have previously received services in school. Services received included speech language pathology and special education. Currently, none of the children have a diagnosed disability; however, one child has had a diagnosis as learning disabled in the past. This is presented in Table 12. 


\section{TABLE 12}

\section{CURRENT SERVICES \\ PREVIOUSLY RECEIVED SERVICES \\ TYPE \\ DIAGNOSED DISABILITY}

$\begin{array}{cccccc}\text { Subject \# } & \begin{array}{c}\text { Current } \\ \text { Services }\end{array} & \begin{array}{c}\text { Previous } \\ \text { Services }\end{array} & \text { Type } & \begin{array}{c}\text { Diagnosed } \\ \text { Disability }\end{array} \\ 012 & \text { no } & \text { yes } & & \text { SLP } & \text { n/a } \\ 085 & \text { no } & \text { yes } & \text { Spec. Ed. } & \text { n/a } \\ 092 & \text { no } & \text { yes } & \text { SLP } & \text { n/a } \\ 094 & \text { no } & \text { no } & \text { n/a } & \text { n/a }\end{array}$

Most of the parents did not list speech and language learning as a concern; however, one parent indicated a concern. In addition, friendships are not a concern for the group; however, one parent is concerned. All of the children were reported to be able to get along with others. This is presented in Table 13. 


\section{TABLE 13}

\section{SPEECH \& LANGUAGE CONCERNS}

FRIENDSHIP CONCERNS

ABILITY TO GET ALONG WITH OTHERS

\section{Speech/Language Friendship Ability to Get \\ Subject \# Concerns $\quad$ Concerns Along with Others}

$\begin{array}{llll}012 & \text { no } & \text { no } & \text { yes } \\ 094 & \text { no } & \text { no } & \text { yes } \\ 085 & \text { yes } & \text { no } & \text { yes } \\ 092 & \text { no } & \text { no } & \text { yes }\end{array}$

Most of the children did not have behavior problems; however, one parent did indicate behavioral issues. None of the children were reported to have motor involvement. This is presented in Table 14.

TABLE 14

BEHAVIORAL PROBLEMS

MOTOR PROBLEMS

$\underline{\text { Subject \# Behavior Problems } \quad \text { Motor Problems }}$

012 no no

085 yes no

092 no no

094 no no 


\section{DISCUSSION}

The ELD group reported results similar to the HELD group on liking to read, reading for fun outside of school, reading like peers, and both groups have similar reading interests like "Goosebumps". However, there was a difference in reading which was the ELD group had an interest in comic book reading, and appeared to do less real book reading. In addition, both groups appeared to have similar best and worst subjects in school. Parents of both groups reported similar results stating that school is difficult for their children.

The ELD group reported results similar to the HELD group on liking school and on succeeding in school. Most of the ELD group and half of the HELD group were reported to be struggling with school.

Although most of the ELD group and none of the HELD group are currently receiving special services in school, most of the ELD and most of the HELD children have received special services in the past. In addition, all parents of both groups agreed the special services were beneficial.

A difference was noted in the current status of documented disability. At the present time, most of ELD children have documented disabilities of learning disabled and autism, while none of the HELD children have documented disabilities.

The ELD group reported similar results to the HELD group regarding concern for speech and language learning, concern for friendships, and ability 
to get along with others. A difference was noted in that the ELD group reported the children have one close friend or only acquaintances, while the HELD children were reported to have several friends. The ELD group reported similar results to the HELD group in play interests involving sports activities such as basketball, baseball, and rollerblading. However, there were differences in that the HELD group reported literacy related play activities such as writing to pen-pals, writing plays and reading which the ELD group did not report.

The ELD group reported similar results to the HELD group in regards to behavioral problems. In regards to motor problems, most of the ELD group reported motor difficulty involving coordination, that the HELD group did not report. 


\section{CHAPTER V \\ SUMMARY AND IMPLICATIONS}

\section{SUMMARY}

Current research in early language development suggests that children who were diagnosed during preschool with expressive language delay would demonstrate difficulties during elementary school years (Scarborough and Dobrich, 1990). This purpose of the present study was to qualitatively describe the outcome of children with a history of early language delay and differing levels of expressive performance (ELD and HELD), as reported by the parents. A questionnaire was developed to determine the children's current age and grade level, past and present reading ability and reading interests, best and worst academic subject, special services and diagnosed disability, speech and language concerns, friendships concerns, and behavioral and motor issues. The study used the results of Lee's (1974) Developmental Sentence Scoring, which determined which children continued to function below the normal range at second grade. Once identified, these children were placed into two groups indicating early language delay (ELD) and history of early language delay (HELD). The data was collected from parent interviews and placed into tables for analysis. Case vignettes were developed for each 
ELD and HELD subject. The suggested trends from the study include: Differences in reading material, literacy related play activities, number of friends, and similar special services received in school. 


\section{IMPLICATIONS}

\section{Clinical}

The results of this study indicate that children with a history of SELD, are seen by parents as succeeding in school. Yet the children with ELD displayed some differences from the HELD group. Both ELD and HELD groups reported receiving similar special services in primary grades in school. This suggests both groups were continuing to have problems in early grades, and that early language delay is a risk factor. This suggests that even though the HELD children grew out of their oral language impairments, they continued to experience difficulties in school.

The ELD children reported reading comic books, which the HELD group did not report. This suggests a possible higher level reading comprehension ability in the HELD group. The ELD group may benefit from exposure to conventional literature in order to help them further develop literacy skills.

The ELD children were reported to have fewer friends than the HELD children. This suggests that the ELD group may have more difficulties with social interactions, which may be related to the continued language difficulties experienced by the ELD group. This suggests that the ELD children may benefit from social programs to help them better relate with peers and/or adults.

The ELD children did not report participating in literacy related play activities with their friends, as did the HELD group. This suggests that ELD 
children do not chose activities centering around reading or writing skills, which may be related to the continued language difficulties experienced by the ELD group. This suggests that the ELD children may benefit by becoming involved in a school newspaper, yearbook, or a pen-pal club in order to further develop literacy skills outside of the classroom.

In addition, parents should be counseled in regards to the likelihood of their child not outgrowing the language delay. The speech-language pathologist should present information on the percentages of SELD children who have learning difficulties. This will allow the parents to make decisions regarding remediation programs.

\section{Research}

Future research is necessary to better understand the effects of early language delay on later academic and social abilities. This research should include statistical studies to further distinguish differences between ELD and HELD groups. Other possible research should involve comparing the ELD and HELD results with those of the normal group using the questionnaire from the current study. This would help provide information to determine if the trends identified in this study are possible results of the early language delay. The ELD group reported reading comic books which was not indicated in the HELD group. As the children advance through school, and as demands increase, more information will be learned through reading. Studies on 
reading ability would be beneficial to determine the effects of early language delay as demands increase. The ELD group was also reported to have fewer friends than the HELD group, therefore an analysis of the children's social behaviors would indicate social aptitude. This research would provide more evidence to support or disclaim the trends identified in this study, as well as past and present research in the area of early language delay and its effects on later outcomes. 


\section{REFERENCES}

Aram, D.M., \& Nation, J.E. (1980). Preschool language disorders and subsequent language and academic difficulties. Journal of Communication Disorders, 13, 159-170.

Bayley, N. (1969). Scales of infant mental development. New York: Psychological Corporation.

Bishop, D.V.M., \& Adams, C. (1990). A prospective study of the relationship between specific language impairment, phonological disorders and reading retardation. Journal of Child Psychology and Psychiatry, 33, 366.

Bishop, D.V.M., \& Edmundson, A. (1987). Language-impaired 4-yearolds: Distinguishing transient from persistent impairment. Journal of Speech and Hearing Disorders, 52, 156-173.

Catts, H., \& Kamhi, A. (1986). The linguistic basis for reading disorders: Implications for the speech-language pathologist. Language, Speech, and Hearing Services in Schools, 17, 329-341. 
Catts, H., \& Kamhi, A. (1989). Reading disabilities: A developmental language perspective. New York: Allyn and Bacon.

Fischel, J., Whitehurst, G., \& Connors, G. (1987). Language growth in children with expressive language delay. Paper presented at the biennial meeting of the Society for Research in Child Development, Baltimore, MD.

Hall, K., \& Tomblin, J. (1978). A follow-up study of children with articulation and language disorders. Journal of Speech and Hearing Disorders, 43, 227-241.

Haynes, C., \& Naidoo, S. (1991). Children with specific speech and language impairment. New York: Cambridge University Press.

Kirk, J., \& Miller, M.L. (1986). Reliability and validity in qualitative research. Newbury Park, CA: Sage.

Lecompte, M.D., \& Goetz, J.P. (1982). Problems of reliability and validity in ethnographic research. Review of Education Research, 52, 31-60. 
Lee, L. (1974). Developmental Sentence Analysis. Northwestern University Press, Evanston, III.

Leonard, L. (1989). Language learnability and specific language impairment in children. Applied Psycholinguistics, 10, 179-202.

Lofland, J., \& Lofland, L.H. (1984). Analyzing social settings: A guide to qualitative observation and analysis. Belmont, CA: Wadsworth Publishing Co.

Locke, J.L. (1994). Gradual emergence of developmental language disorders. Journal of Speech and Hearing Research, 37, 608-616.

Marshall, C., \& Rossman, G.B. (1989). Designing qualitative research. Newburry Park, CA: Sage Publications.

Maxwell, S., \& Wallach, G. (1984). The language-learning disabilities connection: Symptoms of early language disability change over time. In G. Wallach \& K. Butler (Eds.), Language and Learning Disabilities in SchoolAged Children. Baltimore, MD: Williams \& Wilkins.

McCracken, G., (1988). The long interview. Newburry Park, CA: Sage Publications. 
Meyers, J.K., \& Bean, L.L. (1968). A decade late: A follow-up of social class and mental illness. New York: Wiley \& Sons.

Newcomer, P.L., \& Hammill, D.D. (1982). Test of language development: Primary. Austin, TX: Pro-Ed.

Paul, R. (1991) Profiles of toddlers with slow expressive language development. Topics in Language Disorders, 11, 1-13.

Paul, R. (1993). Patterns of development in late talkers: Preschool years. Journal of Childhood Communication Disorders, 15, 7-14.

Paul, R., \& Cohen, D. (1984). Outcomes of severe disorders of language acquisition. Journal of Autism and Developmental Disorders, 14, 405-422.

Paul, R., Laszlo, C.M., McFarland, L.S., \& Midford, N. (1993). Language outcomes in late-talkers: Kindergarten. Society for Research in Child Development Abstracts, 9,534 . 
Paul, R., Spangle-Looney, S., \& Dahm, P. (1991). Communication and socialization skills at ages 2 and 3 in "late-talking" young children. Journal of Speech and Hearing Research, 34, 858-865.

Rescorla, L. (1989). The language development survey: A screening tool for language delay in toddlers. Journal of Speech and Hearing Disorders, 54, 587-599.

Rescorla, L. (1991). Identifying expressive language delay at age two. Topics in Language Disorders, 11, 14-20.

Rescorla, L., \& Schwartz, E. (1990). Outcome of toddlers with specific expressive language delay. Applied Psycholinguistics, 11, 393-407.

Reynell, J. (1983). Developmental Language Scale. London: NFER Nelson.

Scarborough, H.S., \& Dobrich, W. (1990). Development of children with early language delay. Journal of Speech and Hearing Research, 33, 70-83.

Schery, T.K. (1985). Correlates of language development in languagedisordered children. Journal of Speech and Hearing Disorders, 50, 73-83. 
Tallal, P. (1988). Developmental language disorders. In J.K. Kavanagh \& T.J. Truss, Jr. (Eds.), Learning disabilities: Proceedings of the national conference (pp. 181-272). Maryland: York Press/Parkton.

Thal, D., \& Tobias, S. (1994). Relationships between language and gesture in normally developing and late-talking toddlers. Journal of Speech Hearing Research, 37, 157-170.

Thal, D., Tobias, S., Morrison, D. (1991). Language and gesture in late talkers: A one year follow-up. Journal of Speech and Hearing Disorders, 34, $604-612$.

Weiner, P.S. (1985). The value of follow-up studies. Topics in Language Disorders, 5, 78-92.

Whitehurst, G.J., Fischel, J.E., Arnold, D.S., \& Lonigan, CJ (1992). Evaluating outcomes with children with expressive language delay. In S.F. Warren \& J. Reichle (Eds), Causes and effects in communication and language intervention, Vol. I (pp. 277-313). Baltimore: MD: Brookes Publishing. 
Whitehurst, G.J., \& Fischel, J.E. (1994). Practitioner review: Early developmental language delay: What, if anything, should the clinician do about it? Journal of Child Psychology and Psychiatry, 35, 613-648. 
APPENDIX A

Interview Questions 


\section{Interview Questionnaire}

1. How old is your child now? What is his/her current grade level?

2. When did your child begin reading independently?

3. Does he/she like to read? Does he/she read for fun outside school? What kinds of books?

4. Do you feel your child reads like others the same age?

5. What are your child's best subjects in school? Worst subjects?

6. Does your child like school? Is it difficult for him/her? If so, how?

7. Is your child succeeding in school? Is he/she struggling?

8. Does your child receive any special services in school now? At any other time? If so, what kinds of services? If so, do you believe your child benefits? How? If not, how do you wish your child was being served differently? How?

9. Does your child have any diagnosed disability (e.g. learning disabilities)? If so, how does it affect your child? Your family?

10. Do you have any concerns about your child's speech and language learning? Or friendships?

11. Does your child get along well with others? Does he/she have friends? What does he/she like to do with friends?

12. Does your child have any behavior problems? If so, please describe them. Does your child have any motor problems (clumsy, etc.)? 
APPENDIX B

Human Subject Approval 
OFFICE OF GRADUATE STUDIES AND RESEARCH

Research and Sponsored Projects

DATE: $\quad$ May 30,1995

TO: $\quad$ Tracey Abild-Lane $\quad$ SSN\# 503-90-3491

FROM: for Laurie Skokan. Chair, HSRRC, 1994-95 Givingn Trvabiet

RE: $\quad$ HSRRC Waived Review of Your Application titled "Children with Early Language Delay: A Group Case Study of Their Outcomes at Fourth and Fifth Grade"

Your proposal is exempt from further HSRRC review, and you may proceed with the study.

Even with the exemption above, it was necessary by University policy for you to notify this Committee of the Proposed research and we appreciate your timely attention to this matter. If you make changes in your research protocol, the Committee must be notified. This approval is valid for one year from date of issue.

c: $\quad$ Maureen Orr Eldred

Rhea Paul, Project Advisor 
APPENDIX C

Coding Sheet 


\section{Coding Sheet for Parent Interview}

1. Age:

Grade:

2. Age:

3. Yes/No

Yes/No

Types:

4. Yes/No when compared with reading age of peers

5. Best Subjects

Worst Subjects 
6. Like School Yes/No

\author{
Difficult Yes/No
}

How?

7. Succeeding Yes/No

Struggling Yes/No

8. Special Services (time, type):

Beneficial:

How?

Wish he was served differently? 
How?

9. Type of Disability:

Affects the child:

Affects the family:

10. Speech/Language Learning Yes/No:

Friendship Concerns:

11. Ability to get along with others:

Friends:

What do they do? 
12. Behavior Problems Yes/No:

Type:

Motor Problems Yes/No

Type: 
APPENDIXD

Subject Information 
Subject Personal Information

\begin{tabular}{lllll}
\hline Subject \# & Age a & Sex & SES b & Ethnicity c \\
& & & & \\
ELD Group & & & & \\
015 & 141 & M & 3 & W \\
019 & 141 & F & 3 & W \\
093 & 131 & M & 3 & W \\
097 & 128 & M & 3 & W \\
101 & 129 & F & 4 & W \\
\hline
\end{tabular}

a Age given in months.

b Based on a two factor index based on Myers and Bean (1968), where 1 is the

highest and 5 is the lowest SES rating.

$c W=$ White 
Subject \#

Age a

Sex

SES

Ethnicity c

HELD Group

012

132

$\mathrm{F}$

085

132

092

140

094

138

$M$

$M$

$M$

2

3

W

W

$3 \quad W$

$3 \quad W$

a Age given in months.

b Based on a two factor index based on Myers and Bean (1968), where 1 is the highest and 5 is the lowest SES rating.

$c W=$ White 
Individual DSS Scores

Subject \# DSS Score

\section{ELD Group}

015

6.84

019

6.91

093

6.84

097

6.96

101

7.68 
Subject \#

HELD Group

012

085

092

094

\section{DSS Score}

8.52

10.08

12.24

9.88 